\title{
Genetic Disturbance in Wild Minami-Medaka Populations in the Kyushu Region, Japan
}

\author{
Ryohei Nakao ${ }^{1,2}$, Yuichi Kano ${ }^{3}$, Yuka Iguchi ${ }^{1} \&$ Tadao Kitagawa ${ }^{1}$ \\ ${ }^{1}$ Graduate school of Agriculture, Kindai University, Nakamachi 3327-204, Nara, Nara 631-8505, Japan \\ ${ }^{2}$ Graduate school of Human Development and the Environment, Kobe University, 3-11 Tsurukabuto, Nada-ku, \\ Kobe, Hyogo 657-0026, Japan \\ ${ }^{3}$ Institute of Decision Science for Sustainable Society, Kyushu University, 744 Motooka, Nishi-ku, Fukuoka 819, \\ Japan
}

Correspondence: Tadao Kitagawa, Program in Environmental Management, Graduate School of Agriculture, Kindai University, 3327-204, Nakamachi, Nara, Nara, Japan. E-mail: tkitagaw@nara.kindai.ac.jp

Received: May 16, 2017

Accepted: May 26, 2017

Online Published: June 19, 2017

doi:10.5539/ijb.v9n3p71

URL: https://doi.org/10.5539/ijb.v9n3p71

\begin{abstract}
In wild populations of the Japanese endemic freshwater fish Minami-medaka (Oryzias latipes), genetic disturbances caused by crossing with artificially introduced exotic populations, especially an orange-red commercial variety of medaka commonly called himedaka, have been reported throughout Japan. Minami-medaka populations in the Kyushu-Ryukyu Islands region include many genetically distinct groups, indicating that the region is important for the conservation of genetic diversity in Minami-medaka populations. In this study, genetic analyses using two DNA markers (one for a mitochondrial gene, the other for a nuclear gene) were conducted to reveal the current status of genetic disturbance in wild Minami-medaka populations in the Kyushu-Ryukyu Islands region. In 125 individuals from 18 populations analyzed, one individual, from the northern Kyushu Islands, was found to carry alleles originating from the himedaka strain. Based on the results of all available surveys, including those of the present study, a total of six introgressed populations are currently known in the region. All other populations are considered unaffected. The native genetic diversity of Minami-medaka populations in the Kyushu-Ryukyu Islands region is comparatively well preserved; results of surveys throughout the rest of the range of the species indicate that almost half of all Minami-medaka populations have been introgressed by non-native genes. Conservation measures and regular genetic monitoring are recommended to preserve the genetic diversity of this species.
\end{abstract}

Keywords: conservation, genetic disturbance, himedaka, medaka

\section{Introduction}

Genetic disturbances primarily attributable to the artificial introduction of alien species or populations have been known to decrease genetic diversity in wild populations, and to drive decreases in the long-term survival of native species (Frankham, Ballou, \& Briscoe, 2002; Allendorf, Luikart, \& Aitken, 2013).

Minami-medaka (Oryzias latipes; Asai, Senou, \& Hosoya, 2011), an endemic Japanese freshwater fish, is listed as "Vulnerable" in the Red List of Japan due to degradation and predation pressures caused by invasive alien species (Japanese Ministry of Environment, 2015). In addition to decreasing population sizes caused by invasive species, genetic disturbances in Minami-medaka populations, caused by crossing with artificially introduced exotic populations, have been reported throughout Japan. The primary cause of genetic disturbances in wild Minami-medaka populations is the accidental or intentional introduction of an orange-red commercial variety of medaka commonly called himedaka, which is farmed and sold as an aquarium fish and as a live feeding fish (Nakao, Iguchi, Koyama, Nakai, \& Kitagawa, 2017).

The Kyushu-Ryukyu Islands region, in the south-west of the Japanese Archipelago, consists of Kyushu, third largest of the four major islands in Japan and surrounded by many smaller islands, and the Ryukyu Islands, located south of Kyushu. Allozyme and mitochondrial DNA (mtDNA) studies showed that wild Minami-medaka populations have diverged into nine regional groups (Sakaizumi, 1990; Takehana, Nagai, Matsuda, Tsuchiya, \& Sakaizumi, 2003). The Kyushu-Ryukyu Islands region includes six of these regional groups (Northern Kyushu, 
Western Seto-Inland Sea, Ariake, Osumi, Satsuma, and Ryukyu groups; Figure 1; Sakaizumi, 1990), indicating that the region is critical to the conservation of genetic diversity in wild Minami-medaka. A recent study examining genetic disturbance in wild medaka populations throughout Japan indicated that nearly half of the medaka populations in the country have been introgressed by non-native genes, but that populations in the region around Kyushu remain largely unaltered (Nakao et al., 2017; Figure 1). Another study confirmed this finding, reporting low levels of genetic introgression in medaka populations in the Ryukyu Islands region (Imai, Yonezawa, \& Tachihara, 2017).

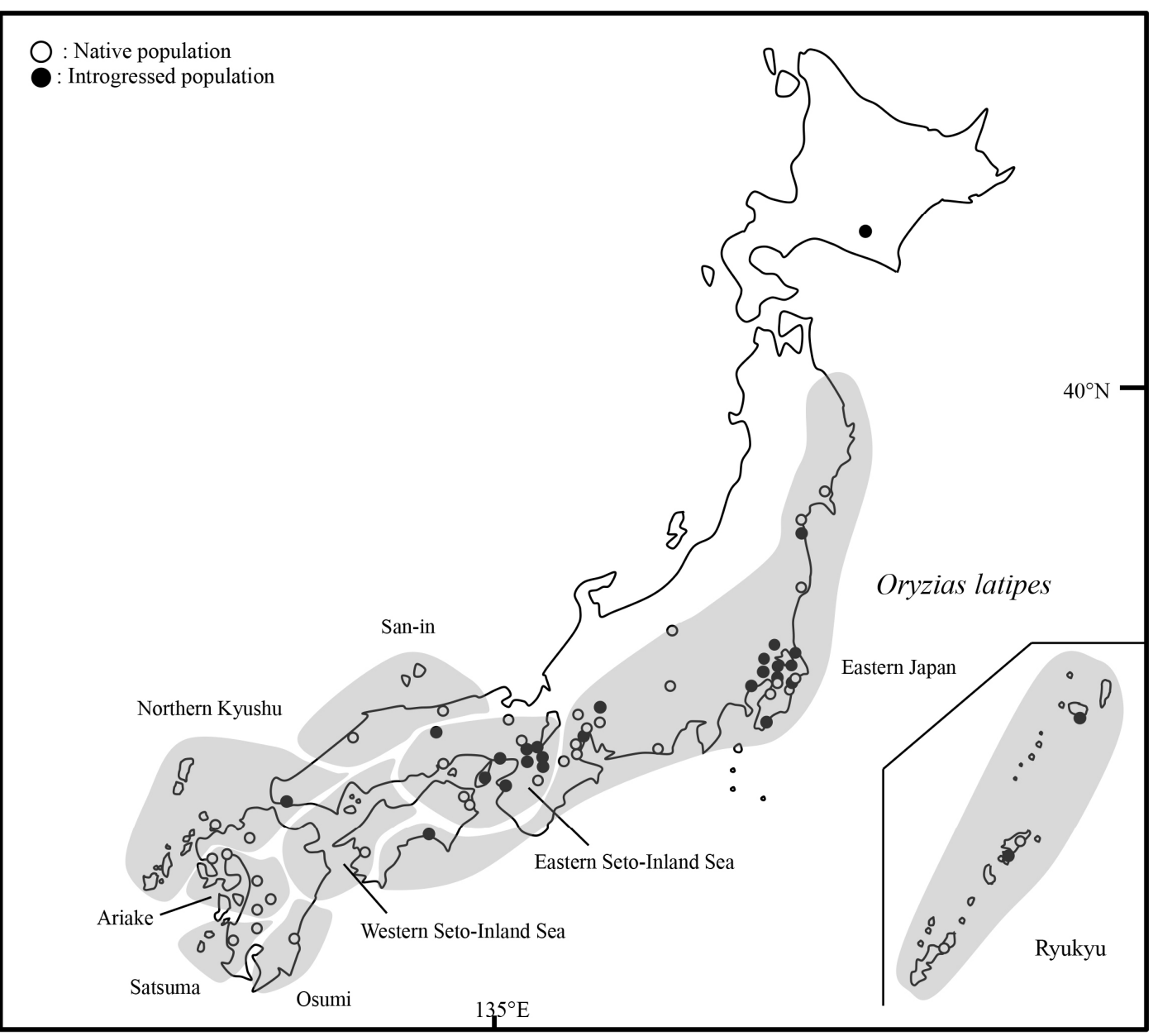

Figure 1. Species range and genetic regional groups of Minami-medaka (Oryzias latipes; gray areas) in Japan. Results reported in a study of genetic disturbance (Nakao et al., 2017) are also shown. Open and solid circles indicate sites of native and introgressed populations, respectively

Recently, however, many species and populations have been artificially introduced to the Kyushu-Ryukyu Islands region, for example three-lips (Opsariichthys uncirostris uncirostris), rosy bittering (Rhodeus ocellatus ocellatus), exotic loach (Paramisgurnus dabryanus), and guppy (Poecilia reticulata; Onikura et al., 2008; Nakajima, Mizutani, \& Fujii, 2012; Shimadzu, 2011). As a result, it is possible that Minami-medaka populations are at risk of invasion and genetic introgression by non-native populations. Although Minami-medaka populations are distributed throughout the three major islands of Japan (Honshu, Shikoku, and Kyushu), populations in Kyushu and the Ryukyu Islands are distributed between many smaller islands. Among these islands, each population is generally small and isolated, and thus more vulnerable to the effects of genetic disturbance. Therefore, it is recommended that medaka populations be monitored regularly, especially in this region.

In this study, to contribute to efforts seeking to conserve genetic diversity in Minami-medaka populations, genetic analyses of two DNA markers were conducted to detect the status of genetic disturbance in wild Minami-medaka populations in Kyushu and the Ryukyu Islands. 


\section{Methods}

\subsection{Sample Collection}

Specimens of $O$. latipes were collected from Kyushu and the Ryukyu Islands from 2013 to 2016, and 125 of these specimens were genetically analyzed (Table 1). One individual with the himedaka phenotype (orange-red body color) was collected from a population in Kyushu (Ky5). Specimens were preserved in $70 \%$ ethanol. Total DNA was extracted from muscle or fin tissues using the phenol:chloroform method (Asahida, Kobayashi, Saitoh, \& Nakayama, 1996). To summarize the present status of genetic disturbance in the region, results from 144 individuals, collected previously from 16 populations in the region (described in Nakao et al., 2017), were also included in the analysis. Three populations in Yakushima Island, Kagoshima Prefecture were collected from artificially managed ponds (Table 1).

Table 1. Survey sites (as in Figure 2), sample size (N), and observed genotypes and mitotypes of Minami-medaka (Oryzias latipes) collected throughout the Kyushu-Ryukyu Islands region. Numbers in parentheses indicate the number of individuals within each site carrying the indicated mitotype and $b$-marker genotype. Refer to Figure 2 for site location details. Year indicates the year in which sites were surveyed. Bold text indicates the himedaka mitotype and genotype; underlined mitotype indicates non-native. ND means not defined (see in the text); * indicates captive bred populations

\begin{tabular}{|c|c|c|c|c|c|}
\hline Site no. & Site location & $\mathrm{N}$ & Year & $b$-marker & Mitotype \\
\hline \multicolumn{6}{|c|}{ Samples collected during the present study: } \\
\hline Ky1 & Kitakyushu, Fukuoka & 4 & - & $B / B(4)$ & B15 (4) \\
\hline $\mathrm{Ky} 2$ & Kurate, Fukuoka & 5 & - & $B / B(5)$ & B15 (5) \\
\hline Ky3 & Naogata, Fukuoka & 2 & 2013 & $B / B(2)$ & $\mathrm{B} 15(2)$ \\
\hline Ky4 & Munakata, Fukuoka & 5 & 2013 & $B / B(5)$ & B15 (5) \\
\hline Ky5 & Kurume, Fukuoka & 3 & 2013 & $B / B(2), \boldsymbol{b} / \boldsymbol{b}(\mathbf{1})$ & B24 (3) \\
\hline Ky6 & Mizuma, Fukuoka & 5 & 2013 & $B / B(5)$ & $\mathrm{B} 24(5)$ \\
\hline Ky7 & Itoshima, Fukuoka & 5 & 2013 & $B / B(5)$ & $\mathrm{B} 15$ (3), B17 (2) \\
\hline Ky8 & Sasebo 2, Nagasaki & 1 & 2013 & $B / B(1)$ & $\mathrm{B} 26(1)$ \\
\hline Ky9 & Higashisonogi, Nagasaki & 5 & 2013 & $B / B(5)$ & $\mathrm{B} 26(5)$ \\
\hline Ky10 & Tsushima 1, Nagasaki & 18 & 2015 & $B / B(18)$ & $\mathrm{B} 15$ (13), B17 (5) \\
\hline Ky11 & Tsushima 2, Nagasaki & 12 & 2015 & $B / B(12)$ & $\mathrm{B} 15(3), \mathrm{B} 17$ (9) \\
\hline Ky12 & Urban Amakusa 1, Kumamoto & 5 & 2013 & $B / B(5)$ & $\mathrm{B} 23(5)$ \\
\hline Ky13 & Urban Amakusa 2, Kumamoto & 5 & 2013 & $B / B(5)$ & B23 (4), ND (1) \\
\hline Ky14 & Rural Amakusa, Kumamoto & 5 & 2013 & $B / B(5)$ & $\mathrm{B} 23(5)$ \\
\hline Ky15 & Ashikita, Kumamoto & 10 & 2013 & $B / B(10)$ & B23 (10) \\
\hline Ky16 & Tanegashima, Kagoshima & 8 & 2016 & $B / B(8)$ & $\mathrm{B} 4(8)$ \\
\hline Ky17 & Amami 2, Kagoshima & 10 & 2016 & $B / B(6)$ & $\mathrm{B} 24(6)$ \\
\hline Ky18 & Izena, Okinawa & 16 & 2016 & $B / B(16)$ & B24 (16) \\
\hline \multicolumn{6}{|c|}{ Samples reported in Nakao et al. (2017): } \\
\hline 90 & Fukuoka, Fukuoka & 10 & 2013 & $B / B(10)$ & $\mathrm{B} 23(1), \mathrm{B} 15$ (9) \\
\hline 91 & Ureshino, Saga & 19 & 2013 & $B / B(19)$ & $\mathrm{B} 23(18), \mathrm{B} 24(1)$ \\
\hline 92 & Kakara, Saga & 14 & 2014 & $B / B(14)$ & B17 (14) \\
\hline 93 & Sasebo 1, Nagasaki & 5 & 2007 & $B / B(5)$ & B24 (1), B26 (4) \\
\hline 94 & Yatsushiro, Kumamoto & 10 & 2013 & $B / B(10)$ & B4 (10) \\
\hline 95 & Kamimashiki, Kumamoto & 3 & 2007 & $B / B(3)$ & $\mathrm{B} 23(3)$ \\
\hline 96 & Tamana, Kumamoto & 8 & 2011 & $B / B(8)$ & $\mathrm{B} 23(1), \mathrm{B} 24(7)$ \\
\hline 97 & Miyazaki, Miyazaki & 14 & 2013 & $B / B(14)$ & B4 (13), ND (1) \\
\hline 98 & Isa, Kagoshima & 10 & 2013 & $B / B(10)$ & $\mathrm{B} 23(10)$ \\
\hline 99 & Ichiki-Kushikino, Kagoshima & 5 & 2013 & $B / B(5)$ & $\mathrm{B} 24(5)$ \\
\hline $100^{*}$ & Yaku-shima 1, Kagoshima & 8 & 2014 & $B / B(7), \boldsymbol{B} / \boldsymbol{b}(\mathbf{1})$ & B24 (7), B1a (1) \\
\hline $101^{*}$ & Yaku-shima 2, Kagoshima & 18 & 2014 & $B / B(14), \boldsymbol{B} / \boldsymbol{b}(4)$ & B11 (5), B27 (13) \\
\hline $102 *$ & Kakeroma, Kagoshima & 2 & 2014 & $B / b(2)$ & B27 (2) \\
\hline 103 & Amami 1, Kagoshima & 5 & 2009 & $B / B(5)$ & B24 (5) \\
\hline 104 & Ogimi, Okinawa & 5 & 2009 & $B / B(5)$ & B24 (5) \\
\hline 105 & Kunigami, Okinawa & 8 & 2014 & $B / B(8)$ & B24 (8) \\
\hline Total & & 269 & & & \\
\hline
\end{tabular}


Following the methods described by Nakao et al. (2017), polymerase chain reaction (PCR) analyses were conducted for two DNA regions: cytochrome $b$ (cyt $b$ ) in the mitochondrial DNA (mtDNA), and a $B$ locus gene involved in the regulation of himedaka body color ( $b$-marker) in the nuclear DNA. PCR-restriction mixtures were formulated, and PCR, electrophoresis, and staining were carried out, according to the methods described by Takehana et al. (2003) for cytb analysis and by Nakai, Nakao, Fukamachi, Koyama, \& Kitagawa (2011) for $b$-marker analysis.

In the analysis of the mtDNA cytb gene, PCR-based Restriction fragment length polymorphism (PCR-RFLP) analysis was performed to identify the local population groups of Minami-medaka, and was carried out using the methods described by Takehana et al. (2003). The mitotype of each individual was determined using combinations of RFLP patterns generated by four or five restriction enzymes, as described by Takehana et al. (2003). An additional sequencing analysis of the cytb gene was carried out in cases where unknown RFLP patterns were detected. Mitotypes corresponding to geographic distributions reported by Takehana et al. (2003) were defined as "native," whereas those that did not meet this criterion were defined as "introgressed," the same protocol used by Nakao et al. (2017). Among the introgressed mitotypes, mitotypes B1a and B27 were further recognized as himedaka-specific mitotypes on the basis of mitotypes previously reported for this population group (Koyama, Mori, Nakai, \& Kitagawa, 2011; Kitagawa, Nakao, Nakai, \& Iguchi, 2017). Introgressed mitotypes that were not identified with himedaka mitotypes, and those originated from other localities, were defined as "non-native." However, a recent study reported that the mitotype B1a includes specimens originating from himedaka populations and from populations in eastern Japan (Iguchi, Nakao, Takata, \& Kitagawa, 2017). To discriminate the precise origin of samples in the present study, additional sequencing analyses of the mtDNA NADH dehydrogenase subunit 2 gene (ND2) were carried out for individuals with mitotype B1a, using the methods described by Iguchi et al. (2017).

A $b$-marker analysis (Nakai et al., 2011), which can detect the alleles of wild medaka and himedaka using PCR amplification, was also carried out. Following the convention used by Nakao et al. (2017), alleles associated with wild medaka were designated $B$, and alleles associated with himedaka were designated $b$.

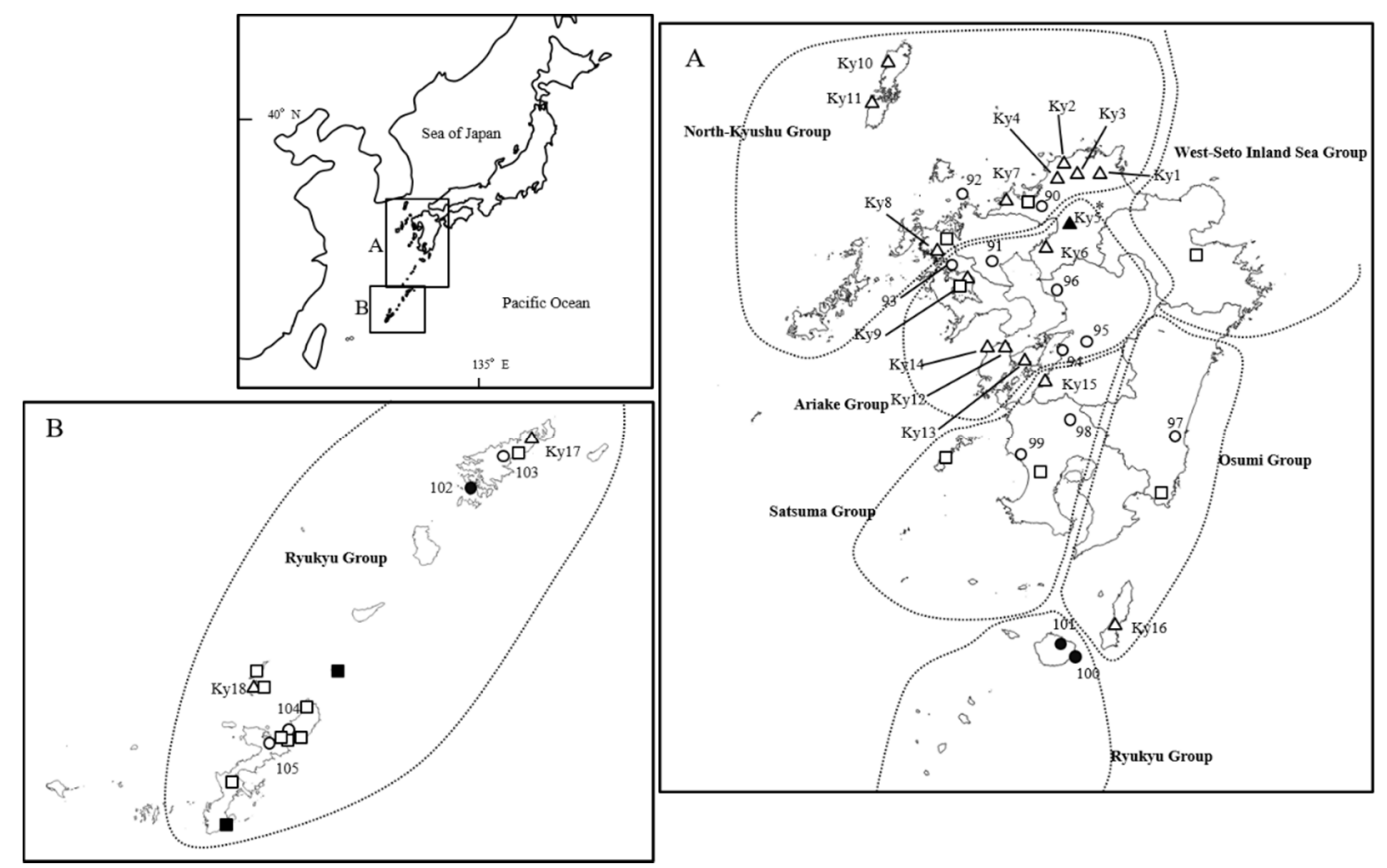

Figure 2. Survey sites and genetic profiles (determined by analyzing cyt $b$ and $b$-marker genes) of wild Minami-medaka (Oryzias latipes) populations in Kyushu and the Ryukyu Islands, Japan. Regions delineated with a broken line indicate the ranges of regional groups as defined by Sakaizumi (1990). Asterisk indicates a site where a himedaka individual was collected (Ky5). Triangles and circles indicate sites surveyed in the present study and in a study conducted by Nakao et al. (2017). Squares indicate the populations detected in genetic analyses carried out in the present study and by Imai et al. (2017). Open and solid shapes indicate the native and introgressed populations, respectively. A: Population ranges in Kyushu. B: Population ranges in the Ryukyu Islands 


\section{Results}

Of the 125 individuals from 18 populations analyzed in the present study, one individual, from site Ky13, had an unknown cyt $b$ gene RFLP pattern. However, additional sequencing of the cytb gene of this individual indicated that it was closely related to the native mitotype B23, from which it differed by only one nucleotide. Another himedaka-phenotype individual collected from site Ky5 was homozygous for the $b$ allele; however, it had the native mitotype B24 (Figure 2; Table 1). Except for this individual, all individuals analyzed in the present study were homozygous for the $B$ allele and had native mitotypes.

Combining the results of the present study with those reported by Nakao et al. (2017), concerning 114 individuals collected from 16 populations, yielded a total of 269 individuals from 34 populations. Of these, 23 individuals from four populations (site Ky5 in Kyushu; sites 100-101 in Yaku-shima; and site 102 in Kakeroma; Table 1) had introgressed mitotypes, the $b$ allele, or both. Mitotype B1a detected from an individual in site 100 was confirmed to be of himedaka origin by ND2 sequencing. Of the four populations with introgressed genotypes, three had been introgressed by the himedaka genotype only (himedaka mitotype and the $b$ allele; Table 1, bold letters), whereas the other (site 101 in Yaku-shima) had been introgressed by both the himedaka mitotype and a non-native mitotype, B11 (Table 1, underlined), identifing with a medaka group in Eastern Japan (Takehana et al., 2003).

\section{Discussion}

The Kyushu region has one of the richest freshwater fish faunas in Japan, comprising both endemic species (e.g., bitterling, Acheilognathus tabira nakamurae; bagrid catfish, Tachysurus aurantiacus; and spined loaches, Cobitis: Cobitis kaibarai, C. matsubarae and C. sakahoko and a population of Chinese bleak (Aphyocypris chinensis; Watanabe, 1998; Onikura et al., 2008). Whereas most areas of the Japanese Archipelago fall in the temperate zone, the Ryukyu Islands are located in the subtropical zone and were geographically isolated from other area for 20,000 years. The Ryukyu Islands provide habitats for a freshwater fish fauna that is unique in Japan and includes tropical taxa (e.g., paradise fish, Macropodus opercularis; freshwater goby, Rhinogobius sp. BB; and Asian swamp eel, Monopterus albus). Although Kyushu and the Ryukyu Islands comprise one of the most important regions for freshwater biodiversity in Japan, native freshwater fish faunas have recently been threatened by the introduction of invasive species. Various tropical species originally introduced as aquarium fishes have invaded and replaced native species, especially in the Ryukyu Islands, including topminnow (Gambusia affinis), guppy (Poecilia reticulata), Nile tilapia (Oreochromis niloticus), and suckermouth armored catfish (Liposarcus disjunctivus; Shimadzu, 2011; Ishikawa, Takada, Tokunaga, \& Tachihara, 2013). The population sizes of the wild Minami-medaka have reportedly been declining due to ecological competition with guppy in particular (Sawara \& Kochi, 1980), and ongoing invasions or expansions by the introduced species.

The Kyushu-Ryukyu Islands region is important for conserving the genetic diversity of Minami-medaka because it provides habitats for several genetically differentiated regional groups (Figure 1). The majority of genetic disturbances detected in Minami-medaka populations are caused by the artificial introduction of himedaka populations. Previous studies have demonstrated that mating between himedaka and wild Minami-medaka in the wild is possible (Nakao \& Kitagawa, 2015), and that the subsequent dispersal of non-native genes throughout waterways is rapid (Nakao, Iguchi, Zhou, Kamide, Kitagawa \& Kobayashi, unpublished). Regular investigations are necessary to monitor invasions by alien species or populations and to conserve native groups of Minami-medaka in the region.

In a recent study investigating populations in the Kyushu Islands (Nakao et al., 2017), we detected non-native genotypes in populations in the Yaku-shima and Kakeroma-jima Islands (sites 100-102). These populations were actually found in artificially managed ponds, and likely to be easily influenced. In one population (site 101), mitotype B11, native to Minami-medaka inhabiting eastern Japan, was detected alongside himedaka genotypes (the $b$ allele and mitotype B27). This indicates a secondary introgression, originating from an already introgressed population in the Eastern Japan Minami-medaka group. In the present study, one individual with the himedaka phenotype, carrying the homozygous $b b$ genotype, was detected in a population of Minami-medaka in Kyushu (site Ky5). Himedaka, the most popular commercial aquarium fish derived from Minami-medaka, is available for purchase in aquarium shops throughout Japan, and is identifiable by specific mitotypes (B27 or B1a; Koyama et al., 2011; Kitagawa et al., 2017). The himedaka phenotype individual collected in the present study had mitotype B24, a mitotype native to the Kyushu region. This result indicates that the individual was not recently introduced; it is rather a descendant of himedaka introduced at least two generations ago $\left(\mathrm{F}_{2}\right)$. Therefore, the population from which it was collected (site Ky5) should be considered introgressed. Although a few individuals from this population were analyzed in the present study, it is possible that it contains high proportions of the $b$ allele, originating from introduced himedaka. 
Previous research on 18 populations in the Ryukyu Islands, conducted from 2003 to 2010, detected non-native genotypes, including himedaka genotypes, in two island populations, one in Yoron-tou and the other in Okinawa-tou (Imai et al., 2017). Our investigations of 34 populations, conducted from 2009 to 2016, serve to provide additional recent information confirming the existence of four additional introgressed populations in the Kyushu-Ryukyu Islands region (Table 1). Based on all available data, six introgressed populations are currently known; the remaining populations are considered native (Figure 3). Some of the sites sampled in the previous study (Imai et al., 2017) and in recent studies (Nakao et al., 2017; the present study) overlapped (sites Ky17, Ky18, and 104 in the present study); no introgressed genotypes were detected in any of these sites at any time. This absence of introgressed genotypes indicates that recent introductions have not occurred in these populations.

\section{Conclusion}

The native genetic diversity of the Minami-medaka populations in the Kyushu-Ryukyu Islands region is better preserved than that of other regions of Japan (Nakao et al., 2017), where almost half of Minami-medaka populations studied have been introgressed by non-native genes. The regional genetic groupings of Minami-medaka proposed by Sakaizumi (1990), which corresponded almost exactly to the evolutionary significant units (ESUs) detected by Moritz (1994), can be considered the basic units of conservation for Minami-medaka populations. The present study reveals that the genetic structures of these regional groups have been preserved in the Kyushu-Ryukyu Islands region. Conservation action and regular genetic monitoring are recommended to preserve the genetic diversity of Minami-medaka.

\section{Acknowledgments}

We thank M. Maegata, S. Kawase, K. Tanaka (Kindai University), and N. Oshiro for assisting in specimen collection. We are grateful to the members of the Aquatic Ecology Laboratory of Kindai Univeristy for their assistance with specimen sampling and field work. Sample collection was partially supported by "Development of mitigation and adaptation technologies to climate change in the sectors of agriculture, forestry, and fisheries" by Ministry of Agriculture, Forestry and Fisheries, Japan.

\section{References}

Allendorf, F. W., Luikart, G., \& Aitken, S. N. (2013). Conservation and the genetics of populations (2nd ed.). New Jersey, USA: Wiley-Blackwell.

Asahida, T., Kobayashi, T., Saitoh, K., \& Nakayama, T. (1996). Tissue preservation and total DNA extraction from fish stored at ambient temperature using buffers containing high concentration of urea. Fisheries Science, 62, 727-730. http://doi.org/10.2331 fishsci.62.727

Asai, T., Senou, H., \& Hosoya, K. (2011). Oryzias sakaizumii, a new ricefish from northern Japan (Teleostei: Adrianichthydae). Ichthyological Exploration of Freshwaters, 22, 289-299.

Frankham, R., Ballou, J. D., \& Briscoe, D. A. (2002). Introduction to conservation genetics. Cambridge, England: Cambridge University Press. https://doi.org/10.1017/CBO9780511808999

Iguchi, Y., Nakao, R., Takata, K., \& Kitagawa, T. (2017). Re-examination of the native mitotype within wild populations of Japanese medaka (Oryzias latipes) in the Kanto region, Japan. Japanese Journal of Ichthyology, 64, 11-18 (in Japanese).

Imai, H., Yonezawa, T., \& Tachihara, K. (2017). First evidence of genetic markers for introgression of non-native genes into unique Ryukyu subpopulation of Oryzias latipes. Bulletin of the Biogeographical Society of Japan, 71, 121-129 (in Japanese).

Ishikawa, T., Takada, M., Tokunaga, K., \& Tachihara, K. (2013). Current status and distribution patterns of non-native freshwater fish on Okinawa-jima Island. Japanese Journal of Conservation Ecology, 18, 5-18 (in Japanese).

Japanese Ministry of Environment (2015). Red list 2015 in Japan. Retrieved April 13, 2017, from http://www.env.go.jp/press/101457.html (in Japanese).

Kitagawa, T., Nakao, R., Nakai, K. \& Iguchi, Y. (2017). Genetic diversity of Japanese wild medaka populations and genetic characteristics of commercial varieties of medaka. Aquabiology, 39, 120-125 (in Japanese).

Koyama, N., Mori, M., Nakai, K., \& Kitagawa, T. (2011). Genetic composition of commercial strains of Oryzias latipes revealed by mtDNA analyses. Japanese Journal of Ichthyology, 58, 81-86 (in Japanese). http://doi.org/10.11369/jji.58.81 
Moritz, C. 1994. Defining 'Evolutionary Significant Units' for conservation. Trends in Ecology and Evolution, 10, 373-375. https://doi.org/10.1016/0169-5347(94)90057-4

Nakai, K., Nakao, R., Fukamachi, S., Koyama, N., \& Kitagawa, T. (2011). Genetic analysis of wild medaka (Oryzias latipes) populations in the Yamato River, Nara Prefecture, Japan: Detection of the $b$ allele responsible for the "himedaka" phenotype. Japanese Journal of Ichthyology, 58, 189-193 (in Japanese). http://doi.org/10.11369/jji.58.189

Nakajima, J., Mizutani, H., \& Fujii, N. (2012). Report of the precautious alien species Paramisgrunus dabryanus (Cobitidae) in Kumamoto Prefecture, Kyushu Island, Japan. Bulletin of the Hoshizaki Green Foundation, 15, 179-181 (in Japanese).

Nakao, R., \& Kitagawa, T. (2015). Differences in the behavior and ecology of wild medaka (Oryzias latipes complex) and an orange commercial variety (himedaka). Journal of Experimental Zoology, 323A, 349-358. http://dx.doi.org/10.1002/jez.1916

Nakao, R., Iguchi, Y., Koyama, N., Nakai, K., \& Kitagawa, T. (2017). Current status of genetic disturbances in wild medaka populations (Oryzias latipes species complex) in Japan. Ichthyological Research, 64, 116-119. http://doi.org/10.1007/s10228-016-0528-5

Onikura, N., Nakajima, J., Eguchi, K., Miyake, T., Kawamura, K., Kurita, Y., ... Kawaguchi, Y. (2008). Present distribution of exotic species in creeks around the Sea of Ariake and Yatsushiro, Northwestern Kyushu, Japan. Journal of the Japanese Society for Water Environments, 31, 395-401 (in Japanese). http://doi.org/10.2965/jswe.31.395

Sakaizumi, M. (1990). Intraspecific variation in Japanese medaka, from genetic analysis. In: N., Egami, K., Yamazaki, A., Shima (Eds.), Biology of medaka (pp. 143-161). Tokyo, Japan: Tokyo University Press (in Japanese).

Sawara, Y., \& Kochi, R. (1980). Mosquitofish (Gambusia affinis). In: T. Kawai, H. Kawanabe, \& N. Mizuno (Eds.), Freshwater organisms in Japan: Ecology of invasion and disturbance (pp. 106-117) (194pp+26pp). Kanagawa, Japan: Tokai University Press (in Japanese).

Shimadzu, N. (2011). A distribution record of alien aquatic organisms and native fishes in 300 water systems on Okinawa Island in the summer of 2010. Japanese Journal of Conservation Ecology, 16, 99-110 (in Japanese).

Takehana, Y., Nagai, N., Matsuda, M., Tsuchiya, K., \& Sakaizumi, M. (2003). Geographic variation and diversity of the cytochrome $b$ gene in Japanese wild populations of medaka, Oryzias latipes. Zoological Science, 20, 1279-1291. http://dx.doi.org/10.2108/zsj.20.1279

Watanabe, K. (1998). Parsimony analysis of the distribution pattern of Japanese primary freshwater fishes, and its application to the distribution of the bagrid catfishes. Ichthyological Research, 45, 259-270. http://doi.org/10.1007/BF02673924

\section{Copyrights}

Copyright for this article is retained by the author(s), with first publication rights granted to the journal.

This is an open-access article distributed under the terms and conditions of the Creative Commons Attribution license (http://creativecommons.org/licenses/by/4.0/). 